\title{
INJÚRIA POTENCIAL DE HERBICIDAS DE SOLO AO GIRASSOL. III - Imazaquin e imazethapyr1
}

\author{
NILSON G. FLECK ${ }^{2}$ e RIBAS A. VIDAL ${ }^{3}$
}

\begin{abstract}
RESUMO
Conduziu-se um ensaio em campo na Estação Experimental Agronômica da Universidade Federal do Rio Grande do Sul, em Eldorado do Sul, RS, em 1989/90. O objetivo do trabalho foi determinar o efeito residual potencial dos herbicidas imazaquin e imazethapyr, aplicados em três doses à superfície do solo (PRE) ou incorporados no mesmo (PPI), na cultura de girassol. Num sistema de rotação soja-girassol, o efeito residual potencial de imazaquin foi mais acentuado que o de imazethapyr. A atividade herbicida de imazaquin e

imazethapyr não foi dependente do método de aplicação. Imazaquin e imazethapyr, nas maiores doses, promoveram danos iniciais acentuados. As plantas de girassol recuperaram-se dos sintomas de intoxicação de imazethapyr, os quais diminuíram com o decorrer do tempo, mas não se recuperaram das injúrias causadas pelas maiores doses de imazaquin.

Palavras-chave: Helianthus annuus, herbicidas residuais, dissipação de herbicidas, persistência no solo, rotação de culturas, imidazolinonas.
\end{abstract}

\section{ABSTRACT \\ Potential sunflower injury by soil applied herbicides. III - Imazaquin and imazethapyr}

A field experiment was carried-out during 1989/90 at the Eldorado do Sul Experimental Station of Federal University of "Rio Grande do Sul", Brazil, with the objective of evaluating potential injury to sunflower by imazaquin and imazethapyr applied at three different dosages in pre-emergence (PRE) or preplant incorporated (PPI). In a soybeansunflower rotation, imazaquin presents greater potential injury to sunflower than imazethapyr. Imazaquin and imaze

\section{INTRODUÇÃO}

Imazaquin e imazethapyr são herbicidas do grupo químico das imidazolinonas, recomendados para controle seletivo de plantas daninhas na cultura da soja, podendo ser aplicados em pré ou pós-emergência (Shaner et al., 1984).

\footnotetext{
${ }^{1}$ Recebido para publicação em 06/04/93 e na forma revisada em 12,01/94. Extraído da Dissertação apresentada pelo segundo autor para obtenção do grau de Mestre em Fitotecnia pela Fac. de Agron. da Univ. Fed. do Rio Grande do Sul (UFRS), Porto Alegre, RS. Trabalho parcialmente financiado pelo CNPq (Processo n $\left.{ }^{\circ} 414024 / 89-31 \mathrm{AG}\right)$.

${ }^{2}$ Eng $^{\circ}$ Agr $^{\circ}, \mathrm{PhD}$, Prof. Adjunto, Dep. de Plantas de Lavoura, Fac. de Agron., UFRS, Av. Bento Gonçalves, 7712, Caixa Postal 776, CEP 90001-000, Porto Alegre, RS. Bolsista do CNPq.

${ }^{3}$ Eng $^{\mathrm{O}} \mathrm{Agr}^{\mathrm{o}}$, MSc, Prof. Assist., Dep. de Plantas de Lavoura, Faculdade de Agronomia, UFRS.
}

thapyr activities were not dependent on application method. It occurred severe herbicide injury when sunflower was assessed early in the season. Plant height assessed late in the season indicated that sunflower recovered from imazethapyr injury, but not from imazaquin injury.

Additional index words: Helianthus annuus, residual herbicide, dissipation of herbicides, soil persistence, crop rotation, imidazolinones.

Estes produtos são absorvidos tanto pelas raízes como pelas folhas, translocam-se pelo xilema e floema e acumulam-se nas zonas de crescimento. Tais compostos são inibidores não-compe titivos da enzima acetohidroxiácido sintase (AHAS), também conhecida como ace tolactato sintase (ALS) (EC 4.1.3.18), a qual catalisa as reações de síntese dos aminoácidos valina, leucina e isoleucina, reduzindo os níveis destes aminoácidos. Este fato acarreta sérios distúrbios na produção de proteína, interferindo no crescimento celular e promovendo necrose no meristema apical e paralisação do crescimento das plantas (Shaner et al., 1984 e Congleton et al., 1987).

Indicações de rótulo restringem as culturas que podem ser rotacionadas com a soja tratada com imidazolinonas, pelo fato de não se conhecer, com maiores detalhes, os efeitos dos resíduos destes herbicidas para diversas culturas. Sabe-se 
que os principais fatores que determinam a persistência das imidazolino nas são lixi viação (WSSA, 1989), adso rção (Loux et al., 1989) e fotodecomposição (Basham \& Lavy, 1987; Basham et a!., 1987; Stougaard et a!., 1990). A meiavida de imazaquin, estimada em laboratório, foi de 7 meses, pelo que pode apresentar restrição à cultura de milho no periodo de 10 meses após a aplicação (Congleton et a!., 1987 e Renner et a1.,1988) e à cultura do algodão no período de 12 meses após a aplicação (Barnes et al., 1989). Ao aumento da umidade do solo durante a estação de crescimento do milho correspondeu um aumento de dano causado pelo imazaquin. Este fato provavelmente foi devido à maior disponibilidade deste herbicida para as plantas, em função da maior absorção de água pelas mesmas (Congleton et al., 1987 e Renner et al., 1988).

Existe a preocupação dos agricultores que realizam a rotação soja-girassol acerca do efeito das imidazolinonas para a cultura do girassol, pois o intervalo entre a semeadura da soja e a do girassol varia de 7 a 10 meses, e estes herbicidas apresentam persistência relativamente prolongada no solo. Portanto, dependendo das condições ambientais, poderiam ocorrer sintomas de intoxicação nas plantas de girassol. O objetivo deste trabalho foi determinar o efeito residual potencial de imazaquin e imazethapyr sobre a cultura do girassol, visando o sistema de rotação com a cultura da soja.

\section{MATERIAL E MÉTODOS}

O experimento foi conduzido a campo durante a estação de crescimento 1989/90, na Estação Experimental Agronômica (EEA) da Universidade Federal do Rio Grande do Sul (UFRS), localizada no município de Eldorado do Sul, RS, região fisiográfica da Depressão Central do Estado.

O delineamento experimental utilizado foi o de blocos casualizados, com os tratamentos arranjados em parcelas subdivididas, com quatro repetições. Cada bloco foi composto de duas parcelas, às quais foram destinadas as épocas de aplicação dos herbicidas [pré-plantio incorporado (PPI) e pré-emergência (PRE)]. Cada parcela foi dividida em 42 unidades experimentais (subparcelas), nas quais foram aplicados, de forma aleatória, os tratamentos herbicidas. A área total da parcela foi de $120 \mathrm{~m}^{2}$ (4 x 30m); a da subparcela foi de $10 \mathrm{~m}^{2}(2,5 \mathrm{x} 4 \mathrm{~m})$, com uma área útil central de 4,5 $\mathrm{m}^{2}(1,5$ $\mathrm{x} 3 \mathrm{~m})$. A cada bloco acrescentou-se uma área extra de $10 \mathrm{~m} 2$ $(2,5 \mathrm{x} 4 \mathrm{~m})$ destinada à testemunha não tratada com herbicida de solo. Cada repetição apresentou, portanto, 25 unidades experimentais (subparcelas).

Em cada época de aplicação (parcela) os tratamentos foram organizados num esquema fatorial hierárquico, isto é, foram utilizados quatro herbicidas (clomazona, clorimuronetil, imazaquin e imazethapyr), cada um deles aplicado em três doses, que corresponderam àquelas usuais, meio e um décimo daquelas recomendadas pela pesquisa para utilização em soja. Este delineamento experimental permite que se apresente aqui apenas os resultados dos herbicidas imazaquin e imazethapyr, os quais foram aplicados nas doses 150 , 75 e $15 \mathrm{~g} / \mathrm{ha}$, e 100,50 e $10 \mathrm{~g} / \mathrm{ha}$, respectivamente.
As informações quanto ao tipo de solo, preparo e adubação do mesmo, aplicações dos herbicidas, semeadura e tratos culturais foram as descritas por Vidal \& Fleck (1994).

Durante os 40 dias após a aplicação dos herbicidas ocorreram precipitações pluviais da ordem de $270 \mathrm{~mm}$.

De cada subparcela foram coletadas, com o auxílio de uma pá, seis plântulas de girassol com raízes, aos 31 dias após a aplicação dos herbicidas, correspondendo a 21 dias após a emergência. As plântulas foram lavadas no momento da coleta para se fazer a separação entre o sistema radicular e o solo. Essas plântulas foram usadas para determinar-se: matéria seca da parte aérea e do sistema radicular, estatura e área foliar. Aos 110 dias após a semeadura, quando as plantas se encontravam no início da maturação fisiológica, determinou-se a estatura média do girassol, avaliando-se 10 plantas por subparcela.

As variáveis avaliadas no experimento foram submetidas à análise de variância de acordo com o modelo de parcelas subdivididas. Quando constatada a significância de dose para os herbicidas imazaquin e imazethapyr ou da interação época de aplicação*dose dos mesmos, procedeu-se ao desdobramento dos graus de liberdade correspondentes, utilizandose a análise de regressão, testando-se a significância da regressão linear e desvios da mesma. Os coeficientes polinomiais ortogonais foram calculados através do método para níveis não-equidistantes, desenvolvido por Nogueira (1979). Determinaram-se as equações lineares significativas e, caso o quadrado médio dos desvios de uma regressão tenha sido significativo, utilizou-se o procedimento apresentado por Gomez \& Gomez (1984).

Cada dose herbicida foi comparada à testemunha (sem aplicação) através do teste DMS, ao nível de 5\% de probabilidade. Optou-se pelo teste DMS, principalmente, para comparar a testemunha com a menor dose testada, uma vez que a análise de regressão já é suficiente para a comparação entre as doses utilizadas (Chew, 1976 e Petersen, 1977).

\section{RESULTADOS E DISCUSSÃO}

Observou-se redução da área foliar com o aumento da dose dos dois produtos (Figura 1). Ocorreu interação entre épocas de aplicação e doses de imazethapyr. $\mathrm{Na}$ menor dose este produto apresentou efeito mais diferenciado entre as duas épocas, sendo que, aplicado em PRE, não diferiu da testemunha, enquanto que, aplicado em PPI, apresentou efeito mais pronunciado. Na maior dose o efeito entre as duas épocas de aplicação foi pouco diferenciado. As plântulas da área tratada com a menor dose de imazaquin desenvolveram menor área foliar em relação às presentes nas áreas tratadas com as menores doses de imazethapyr e na testemunha. Já na maior dose, os efeitos de imazaquin e imazethapyr, nas duas épocas de aplicação, foram equivalentes (Figura 1).

Com incremento na dose dos compostos testados verificou-se redução da matéria seca da parte aérea das plântulas (Figura 2). Nesta avaliação não se registrou interação entre épocas de aplicação e doses dos herbicidas. A resposta de imazaquin na menor dose foi mais acentuada que a de imazethapyr, já na maior dose testada, imazaquin e imazethapyr 


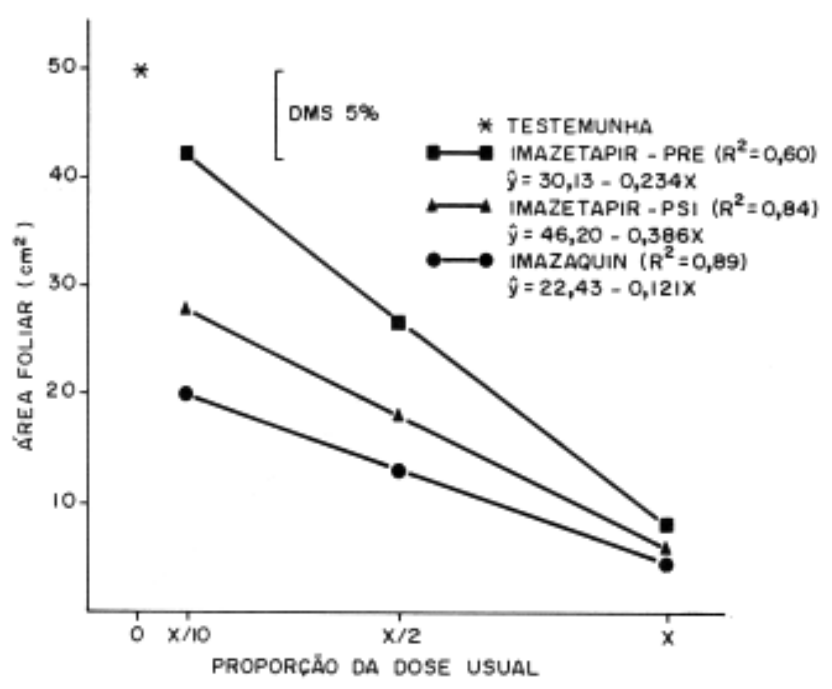

FIG. 1 - Área foliar das plantas de girassol aos 31 dias após aplicaçảo ao solo dos herbicidas imazaquin, na média de duas épocas de aplicação; $\mathrm{e}$ imazethapyr, em duas épocas de aplicaçảo, comparadas à testemunha sem herbicidas. EEA/ UFRS, Eldorado do Sul, RS, 1989/90.

proporcionaram efeitos semelhantes (Figura 2). Constataram-se diferenças significativas entre a fitomassa da parte aérea das plântulas das parcelas testemunhas e as das parcelas tratadas com a menor dose dos dois herbicidas.

Quanto à relação entre matéria seca da parte aérea e matéria seca da parte radicular não houve diferença em função do método de aplicação. Com incremento da dose, os herbicidas promoveram redução da relação parte aérea/raiz. Isto significa que, com o incremento da dose, eles afetaram mais drasticamente a parte aérea do que a parte radicular

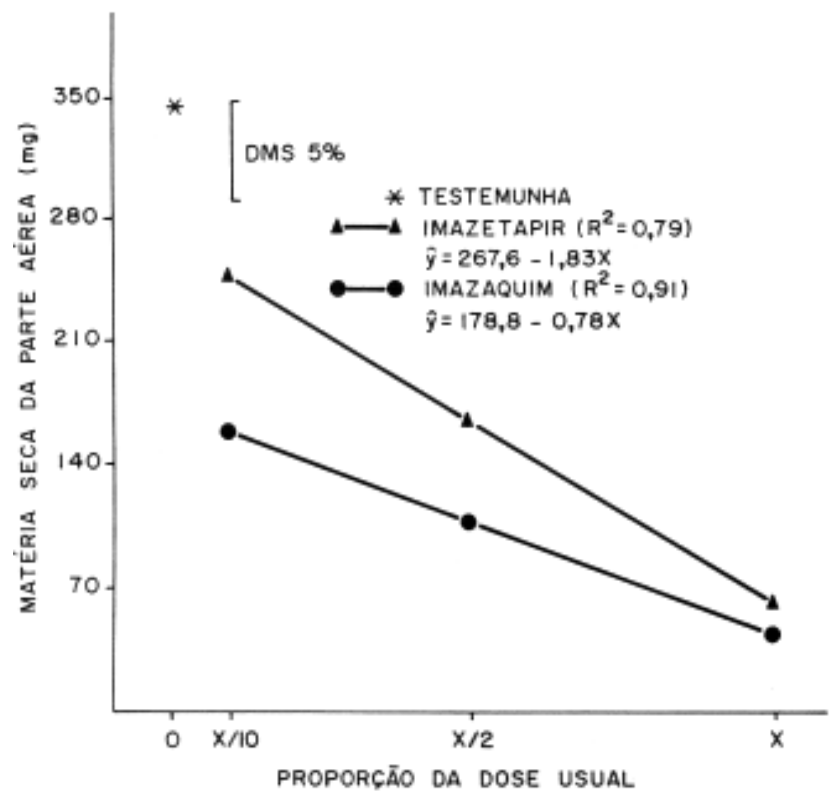

(Figura 2). As plantas tratadas com a menor dose de imazethapyr apresentaram relação similar à da testemunha (Figura 2).

Nas avaliações de estatura das plantas, realizadas tanto aos 31 DAT como aos 110 DAT, imazaquin e imazethapyr não apresentaram comportamento diferenciado em função das épocas de aplicação (Figura 3). Nas duas avaliações, ambos os herbicidas na menor dose não promoveram redução da estatura, quando comparados à testemunha. Contudo, na avaliação realizada aos 31 DAT, promoveram redução linear da mesma com o incremento da dose (Figura 3). Aos 110 DAT, verificou-se redução da estatura com incremento da dose de imazaquin, enquanto plantas tratadas com imazethapyr não mostraram redução desse parâmetro (Figura 3).

$\mathrm{O}$ efeito marcadamente pronunciado de dose de imazethapyr, tanto nas avaliações da parte aérea quanto do sistema radicular das plântulas (Figuras 1 a 3), pode ser atribuído, ao menos em parte, à acentuada adsorção das moléculas do composto aos colóides do solo. A estrutura tridimensional da molécula de imazethapyr lhe confere grande afinidade às cargas iônicas do solo, permitindo que ele tenha grande capacidade de competir com os cátions inorgânicos pelos locais de adsorção (Stougaard et al., 1990). Além disso, a adsorção de imazethapyr é pouco dependente do $\mathrm{pH}$, comparada à de outras imidazolinonas, e a presença de alumínio pode contribuir para a adsorção desse herbicida pelas argilas (Loux et al., 1989).

Esta argumentação pode ser empregada também para justificar, ao menos parcialmente, a interação significativa de épocas de aplicação e doses de imazethapyr na avaliação da área foliar (Figura 1). Constatou-se efeito mais pronunciado deste herbicida quando aplicado em PRE do que em PSI, principalmente nas menores doses, sendo que esta diferença tendeu a desaparecer cpm o incremento da dose.

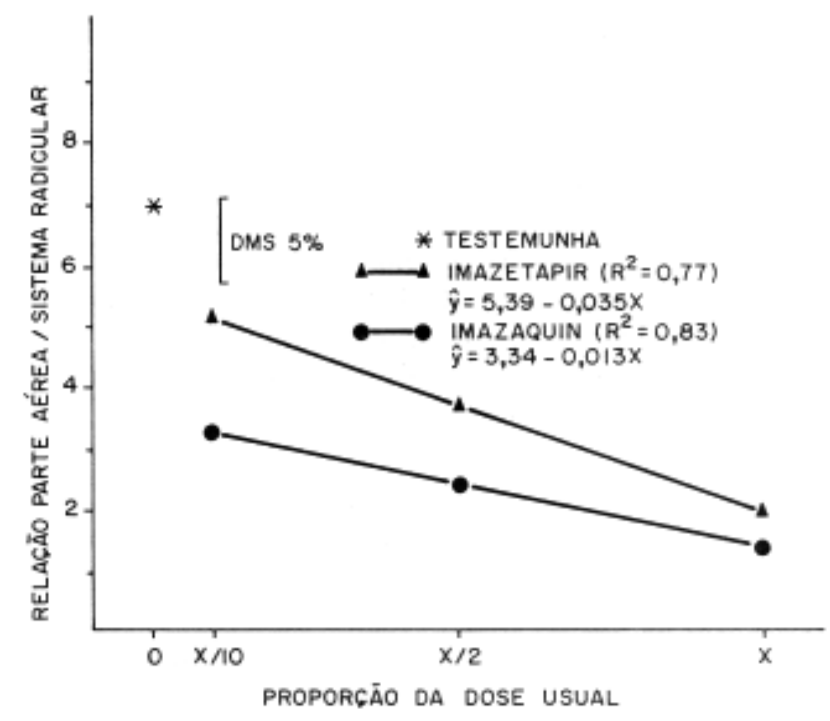

FIG. 2 - Matéria seca da parte aérea e relaçảo entre matéria seca da parte aérea e do sistema radicular das plantas de girassol aos 31 dias após aplicaçáo ao solo dos herbicidas imazaquin e imazethapyr, na média de duas épocas de aplicação, comparadas à testemunha sem herbicidas. EEA/UFRS, Eldorado do Sul, RS, 1989/90.

Planta Daninha, v. 12, n. 1, 1994. 

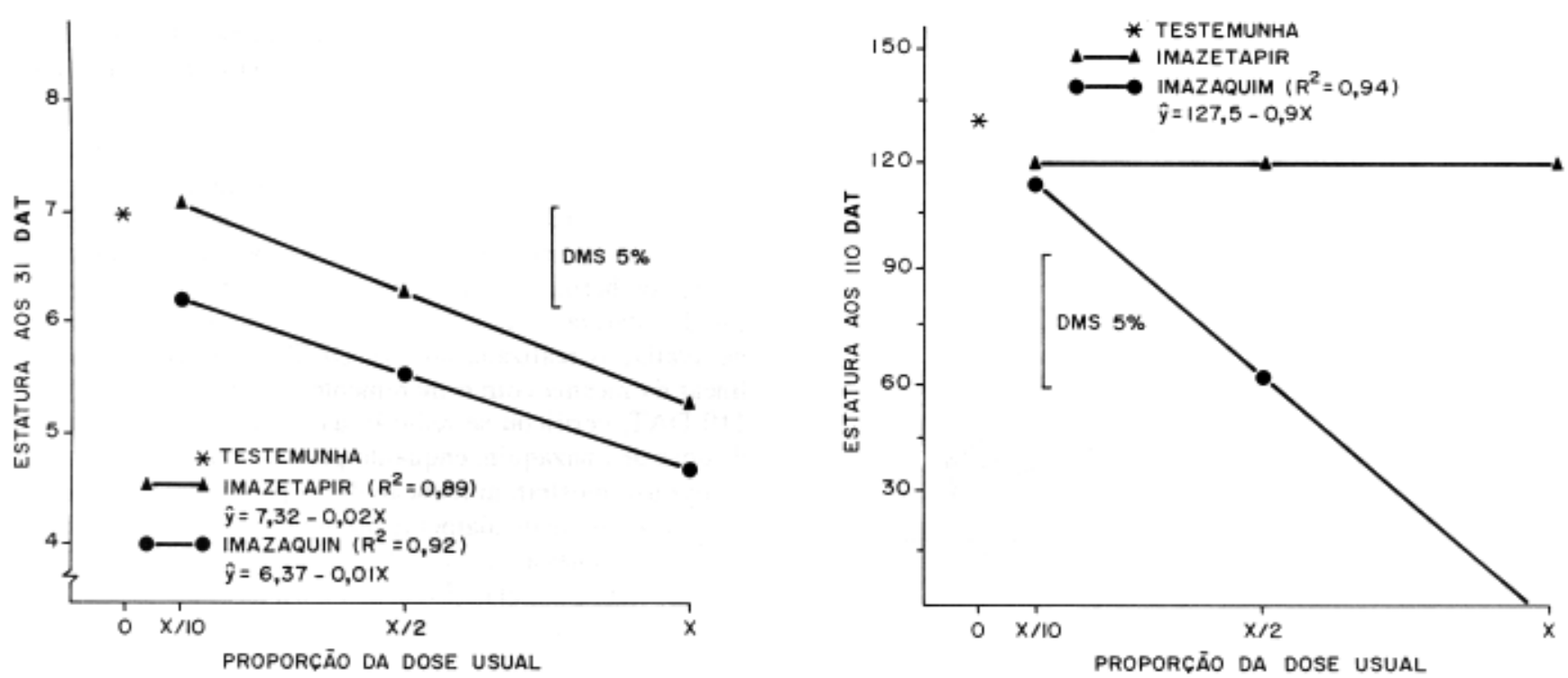

FIG. 3 - Estatura das plantas de girassol aos 31 e 110 dias após aplicação ao solo dos herbicidas imazaquin e imazethapyr, na média de duas épocas de aplicaçấo, comparadas à testemunha sem herbicidas. EEA/UFRS, Eldorado do Sul, RS, 1989/90.

Outra hipótese que poderia explicar a reduzida atividade de imazethapyr nas menores doses seria a possibilidade de que moléculas não adsorvidas sofressem lixiviação, visto que é acentuada a solubilidade do produto em água (1400 mg/1 - WSSA, 1989). Assim, este composto pode ter-se distribuído a uma maior profundidade, não estand o disponível para absorção pelas plântulas.

Nas demais avaliações das plântulas não se obser varam interações de épocas e doses de imazethapyr. Estes resultados estão em conformidade com os obtidos por Andersen (1985), Behrens \& Ford (1985), Gunsolus \& Warnes (1986) e Martin \& Stougaard (1985), todos citados por Cantwell et al. (1989). Estes autores relataram a versatilidade de imazethapyr quanto à época de aplicação. No entanto, o próprio trabalho de Cantwell et a!. (1989) indicou diferenças no desempenho de imazethapyr aplicado em PRE e PPI sob condições de baixa precipitação. Eles evidenciaram a importância da ocorrência de adequada quantidade de chuva para promover o movimento de imazethapyr aplicado em PRE, deixando-o disponível para absorção pelo sistema radicular. A ocorrência de alta pluviosidade no presente experimento, principalmente durante os 40 dias seguintes à aplicação dos herbicidas, pode ter contribuído para distribuir o imazethapyr aplicado em PRE nas maiores doses, deixando-o disponível para absorção pelo girassol.

Nenhuma das avaliações realizadas (Figuras 1 a 3 ) indicou interação de épocas de aplicação e doses de imazaquin. Estes resultados coincidem com os obtidos por Wesley et al. (1989) e Renner et al. (1988), que não constataram diferenças no desempenho deste herbicida, aplicado em PPI e PRE, no controle de diversas espécies daninhas. Estes autores atribuíram tal comportamento à alta ocorrência de precipitações. A chuva, além de propiciar a distribuição do herbicida no perfil do solo, reduz a fotodecomposição que poderia inativá-lo (Basham \& Lavy, 1987; Basham et al., 1987; Stougaard et al., 1990).
Visualmente, constatou-se um atraso no desenvolvimento das plantas tratadas com imazaquin e imazethapyr. Sintomas semelhantes foram constatados por Barnes et al. (1989) que verificaram que imazaquin promoveu atraso de até 3 semanas no desenvolvimento das plantas de algodão. Os efeitos tóxicos de imazaquin nas plantas de girassol puderam ainda ser constatados na avaliação de estatura realizada na maturação fisiológica (Figura 3). No entanto, o mesmo não pode ser observado com o herbicida imazethapyr, pois aparentemente as plantas se recuperaram dos sintomas de intoxicação iniciais.

Utilizando-se as equações de regressão entre matéria seca da parte aérea e doses dos herbicidas (Fígura 2), estimaram-se as doses necessárias para a redução de $50 \%$ da matéria seca da parte aérea em 3 e $50 \%$ da dose usual dos herbicidas imazaquin e imazethapyr, respectivamente. Admitindo-se um intervalo de 210 dias (7 meses) entre a aplicação dos herbicidas e a semeadura do girassol, pode-se utilizar a equação:

$$
\operatorname{Ln}([\mathrm{Cf}] /[\mathrm{Ci}])=-k \mathrm{t}
$$

Esta equação, de acordo com Witt (1989), representa a cinética de degradação de imazaquin e imazethapyr no solo; onde, [Ci] e [Cf] são as concentrações dos herbicidas no tempo inicial e final, $\mathrm{k}$ é a constante de degradação do herbicida, e t é o tempo. Determinou-se que o valor $-\mathrm{k}$ corresponde a 0,0167 e 0,0033 para imazaquin e imazethapyr, respectivamente. Utilizando-se, então, a equação:

$$
\mathrm{t} 1 / 2=0,693 / \mathrm{k}
$$

onde t 1/2 representa a meia-vida do produto (Witt, 1989), estimou-se que a meia-vida dos herbicidas imazaquin e imazethapyr para redução de $50 \%$ na matéria seca seria de 41 e 210 dias, respectivamente. Isto significa que, se houvessem condições ambientais favoráveis para que a meia-vida destes produtos fosse daquela magnitude, ambos seriam injuriosos 
para o girassol. Contudo, trabalhos realizados nos Estados Unidos (Congleton et al., 1987; Renner et al., 1988; Witt, 1989; WSSA, 1989) referem que apenas imazaquin apresenta meia-vida que poderia se enquadrar nas estimativas acima.

Os resultados deste experimento permitem concluir que:

1. a atividade herbicida de imazaquin e imazethapyr não é dependente do método de aplicação no solo;

2. num sistema de rotação soja-girassol, o efeito residual potencial de imazaquin para a cultura de girassol é acentuado;

3. neste sistema, o efeito residual potencial de imazethapyr para a cultura de girassol é reduzido;

4. imazaquin e imazethapyr, nas maiores doses, promovem danos iniciais acentuados nas plantas de girassol;

5. o girassol recupera-se dos sintomas de intoxicação de imazethapyr com o decorrer do tempo;

6. o girassol não se recupera da intoxicação promovida pela dose plena de imazaquin ou metade dela.

\section{AGRADECIMENTOS}

Ao Dr. João Riboldi, do Instituto de Matemática da UFRS, pelo apoio na análise estatística dos resultados.

\section{LITERATURA CITADA}

BARNES, C. J.; GOETZ, A. J.; LAVY, T. L. Effects of imazaquin residues on cotton (Gossypium hirsutum). Weed Science, Champaign, v37, p.820-824, 1989.

BASHAN, G. W.; LAVY, T. L. Microbial and photolytic dissipation of imazaquin in soil. Weed Science, Champaign, v.35, p.865-879, 1987.

BASHAN, G. W.; LAVY, T. L; OLIVER, L. R.; SCOTT, H. D. Imazaquin persistence and mobility in three Arkansas soils. Weed Science, Champaign, v.35, p.576-582, 1987.

CANTWELL, J. R.; LIEBL, R. A.; SLIFE, F. W. Imazethapyr for weed control in soybean (Glycine max). Weed Technology, Champaign, v.3, p.596-601, 1989. CHEW, V. Comparing treatment means: a compendium. HortScience, Alexandria, v.11, n.4, p.348-357, 1976.
CONGLETON, W. F.; VANCANFORT, A. M.; LIGNOWSKI, E. M. Imazaquin (Scepter®): a new soybean herbicide. Weed Technology, Champaign, v.2, p.186-188, 1987.

GOMEZ, K. A.; GOMEZ, A. O. Statistical procedures for agricultural research. 2.ed. New York: John Wiley, 1984. 680p.

LOUX, M. M.; LIEBL, R. A.; SLIFE, F. W. Adsorption of imazaquin and imazethapyr on soils, sediments, and selected adsorbents. Weed Science, Champaign, v.37, p.712-718, 1989.

NOGUEIRA, I. R. Método geral para obtenção de tabelas de polinômios ortogonais. Revista de Agricultura, Piracicaba, v.53, p.269-2'79, 1979.

PETERSEN, R. G. Use and misuse of multiple comparison procedures. Agronomy Journal, Madison, v.69, p.205208, 1977.

RENNER, K. A.; MEGGITT, W. F.; LEAVITT, R. A. Influence of rate, method of application, and tillage on imazaquin persistence in soil. Weed Science, Champaign, v.36, p.9095. 1988.

SHANER, D. L.; ANDERSON, P. C.; STIDHAM, M. A. Imidazolinones, potent inhibitors of acetohydroxyacid synthase. Plant Physiology, Lancaster, v.75, p.545-546, 1984.

STOUGAARD, R. N.; SHEA, P. J.; MARTIN, A. R. Effects of soil type and $\mathrm{pH}$ on adsorption, mobility, and efficacy of imazaquin and imazethapyr. Weed Science, Champaign, v.38, p.67-73, 1990.

VIDAL, R. A.; FLECK, N. G. Injúria potencial de herbicidas de solo ao girassol. I- Clomazone. Planta Daninha, Brasília, v.11, n.1/2, p.36-43, 1993.

WESLEY, R. A.; SHAW, D. R.; BARRENTINE, W. L. Incorporation depths of imazaquin, metribuzin, and chlorimuron for common cocklebur (Xanthium strumarium) control in soybeans (Glycine max). Weed Science, Champaign, v.37, p.596-599, 1989.

WITT, W. W. Persistence of imazaquin, imazethapyr, and clomazone in notill double-crop soybeans. In: CONFERENCIA MUNDIAL DE INVESTIGACIONEN SOYA, 4., 1989, Buenos Aires. Actas ... Buenos Aires: J. A. Pascale, 1989. p.1683-1688.

WSSA. Herbicide handbook. 6.ed. Champaign: WSSA, 1989. 301p. 